\title{
The efficacy of mirabegron additional therapy for lower urinary tract symptoms after treatment with a1-adrenergic receptor blocker monotherapy: prospective analysis of elderly men
}

Tomohiro Matsuo, Yasuyoshi Miyata*, Katsura Kakoki, Miki Yuzuriha, Akihiro Asai, Kojiro Ohba and Hideki Sakai

\begin{abstract}
Background: Mirabegron is a $\beta 3$-adrenoreceptor agonist developed for treatment of overactive bladder (OAB). a1-Adrenergic receptor blockers are effective for lower urinary tract symptoms (LUTS) in male patients. However, the efficacy of mirabegron additional treatment in elderly male patients with persistent male LUTS, especially in $O A B$ after monotherapy with a1-adrenergic blockers, is not fully understood.
\end{abstract}

Methods: This study was conducted in male LUTS patients who were $\geq 65$ years of age and had persistent OAB symptoms, regardless of whether they took an a1-adrenergic receptor blocker orally. Before and 12 weeks after mirabegron additional therapy (50 mg once daily), we evaluated the efficacy of this treatment using the Overactive Bladder Symptom Score (OABSS) and International Prostate Symptom Score (IPSS), and changes in the maximum flow rate (Qmax) and post-void residual urine volume (PVR). We evaluated patients overall and divided into two groups by age: young-old (from 65 to 74 years old) and old-old (from 75 to 84 years old).

Results: Fifty men were enrolled in this study. Mirabegron additional therapy improved the total OABSS, total IPSS, and IPSS-quality of life (QOL) score. The voided volume (W) and Qmax improved after treatment in patients overall. However, there was no significant change in PVR. The total OABSS, total IPSS, and IPSS-QOL score significantly improved in both of the young-old and old-old groups. However, a significant increasing of $\mathrm{W}$ was detected in the young-old group. There were no significant differences in the Qmax or PVR in either group.

Conclusions: Mirabegron additional therapy was effective for male patients whose persistent LUTS and particularly $O A B$ was not controlled with a1-adrenergic receptor blocker monotherapy, and mirabegron did not have negative effects on voiding function. Additionally, mirabegron additional therapy was considered effective regardless of patient age.

Trial registration: Trial registration number (TRN) trial registration number (TRN) and date of registration: ISRCTN16759097 in July 8, 2016.

Keywords: Mirabegron, Elderly male, Overactive bladder, a1-adrenergic blockers

\footnotetext{
* Correspondence: int.doc.miya@m3.dion.ne.jp

Department of Urology, Nagasaki University Graduate School of Biochemical

Sciences, 1-7-1 Sakamoto, Nagasaki 852-8501, Japan
} 


\section{Background}

Overactive bladder $(\mathrm{OAB})$ is defined as a condition with characteristic symptoms of urinary urgency that is usually accompanied by frequency and nocturia, with or without urgency incontinence [1]. It is particularly burdensome to older people because of its higher prevalence, and because the impact of its symptoms may be more pronounced due to the increased burden of chronic comorbidities [2,3]. The symptoms caused by $\mathrm{OAB}$ decrease patients' quality of life (QOL), and $\mathrm{OAB}$ can lead to various pathological conditions such as increases in the fracture rate, sleep disturbances, and depressive feelings) [4, 5]. Anti-muscarinic agents are often used as first-line therapy for patients with OAB. However, unfortunately, about a third quarter of patients cannot continue taking these drugs due to unsatisfactory efficacy and various adverse events $[6,7]$.

In addition, mainly due to the adverse effects of antimuscarinic drugs, Japanese clinical guidelines for both male lower urinary tract symptoms (LUTS) and benign prostatic hyperplasia recommend physicians to use $\alpha 1$ adrenergic blockers as the first choice drug for male LUTS patients regardless of the presence or absence of OAB symptoms $[8,9]$.

Mirabegron is a $\beta 3$-adrenoceptor agonist approved for treating $\mathrm{OAB}$ in Europe, the United States, Canada, Japan, and Australia [10]. Mirabegron is a specific agonist, acting on $\beta 3$-adrenoceptors in the human detrusor, the stimulation of which leads to active relaxation of the human detrusor in the storage phase, which increases bladder capacity without exerting an effect on voiding [11]. The efficacy and safety of mirabegron have been studied in several randomized trials. For example, SCORPIO, a large, randomized, placebo-controlled phase III study, evaluated the efficacy, safety, and tolerability of mirabegron over 12 weeks in patients with OAB [12], and TAURUS, a 1-year, randomized, doubleblind, safety study, evaluated the safety, tolerability, and efficacy of mirabegron [13]. Both studies mainly improved storage symptoms, including urgency incontinence and increased voiding volume, and demonstrated that the efficacy of mirabegron lasted 4 weeks later and continued until the end of the observation periods. Furthermore, the rate of adverse events due to $50 \mathrm{mg}$ mirabegron was similar to that of a placebo, and significantly lower than that of the anti-muscarinic drug tolterodine (4 mg) $[12,13]$. In addition, other researchers have reported that mirabegron add-on therapy combined with $\alpha 1$-adrenergic receptor blockers is very effective for storage symptoms, even in male patients with OAB [14-16]. However, no studies have focused on elderly male patients aged 65 years old and over.

To our knowledge, the present study is the first to focus on the efficacy of mirabegron additional therapy in elderly male patients with $\mathrm{OAB}$ after treatment with $\alpha 1$ adrenergic receptor blocker monotherapy.

\section{Methods}

This prospective study was conducted in male patients who were 65 years or older in age, had persistent LUTS and particularly $\mathrm{OAB}$ symptoms, and had been taking a regular dose of $\alpha 1$-adrenergic receptor blockers for more than 12 weeks. OAB was diagnosed using the Overactive Bladder Symptom Score (OABSS), and persistent OAB symptoms were defined as a total OABSS of 3 or more points with urinary urgency at least once per week [17]. Exclusion criteria were a post-void urine volume (PVR) of $50 \mathrm{~mL}$, history of urinary retention, prior diagnosis of neurogenic bladder, urethral stricture, severe hypertension (systolic blood pressure $\geq 180 \mathrm{mmHg}$ and/or diastolic blood pressure $\geq 110 \mathrm{mmHg}$ ) not well controlled by medication, renal insufficiency (glomerular filtration rate $<30 \mathrm{~mL} / \mathrm{min} / 1.73 \mathrm{~m}^{2}$ ), liver impairment, intention to have a child, urological malignancy, patients taking any anti-muscarinic drugs, or those considered unsuitable for the trial by the treating physicians.

The patients continued all of their prescribed drugs during this study period. Before and 12 weeks after mirabegron (Betanis ${ }^{\oplus}$, Astellas Pharma Inc., Tokyo, Japan; $50 \mathrm{mg}$ once daily) treatment was added to a previous $\alpha 1$-adrenergic receptor blocker for urinary symptoms, we evaluated the efficacy of the treatment using the OABSS and International Prostate Symptom Score (IPSS) to assess subjective symptoms, and we used uroflowmetry and PVR to assess objective symptoms. We measured the maximum flow rate (Qmax) using the Duet $^{\bullet}$ Logic G2 system (Mediwatch UK Ltd., Rugby, UK) on free uroflowmetry and PVR using transabdominal ultrasound sonography (HI VISION Avius ${ }^{\oplus}$ HitachiAloka Medical, Ltd, Tokyo, Japan). Moreover, before mirabegron add-on treatment was administered, we evaluated the prostate volume (PV) using transabdominal ultrasound sonography.

The primary endpoint was the change in total OABSS. The secondary endpoints evaluated were the change in the subscale scores of the OABSS, total IPSS, each subscale score of the IPSS and IPSS-QOL, voided volume (VV) on free uroflowmetry, Qmax, and PVR. In this study, we compared these subjective and objective parameters between two groups defined according to the patients' age: young-old (from 65 to 74 years old) and old-old (from 75 to 84 years old).

During the clinical study, the current $\alpha 1$-adrenergic receptor blocker that the patients had been taking orally was not changed to a different one. Additionally, no patients were taking multiple $\alpha 1$-adrenergic receptor blockers. The safety assessment included a change in adverse events. We observed patients' complaints of 
adverse effects, and information on the adverse events was recorded throughout the study period.

All statistical analyses were performed using computer software (JMP 10; SAS Institute Inc., Cary, NC, USA). Differences in the changes in patients' parameters from baseline to 12 weeks were examined using the Wilcoxon signed-rank test. $P<0.05$ was considered statistically significant.

\section{Results}

Fifty men were enrolled in this study. As shown in Table 1, overall, the mean \pm standard deviation (SD) of patients' age was $75.7 \pm 7.6$ years, and the mean \pm SD PV was $33.7 \pm 8.6 \mathrm{~mL}$. All patients had taken a previous $\alpha 1$ adrenergic receptor blocker, including silodosin (26 patients), naftopidil (15), tamsulosin (8), and urapidil (1). Among the 50 patents, 22 (44.0\%) and 28 (56.0\%) were classified into the young-old group and old-old group, respectively. No other demographic or clinical parameters significantly differed between the young-old and old-old groups.

Figure 1a shows the change in the OABSS before and after mirabegron add-on treatment was administered to patients overall. Mirabegron add-on treatment improved the total OABSS (from $6.0 \pm 2.1$ to $4.4 \pm 1.4, P<0.001$ ), and the nighttime frequency (OABSS Q2, $P<0.001$ ) and urgency (OABSS Q3, $P<0.001$ ) subscale scores of the OABSS after the 12-week treatment period. Although the urgency incontinence subscale score (OABSS Q4) improved after 12 weeks compared to that before treatment, the difference did not reach statistical significance $(P<0.05)$. Similarly, mirabegron add-on treatment significantly improved the total IPSS (before $15.1 \pm 4.2$ to $11.8 \pm 4.6, P<0.001$ ); frequency (IPSS Q2, $P<0.001$ ), urgency (IPSS Q4, $P<0.001$ ), and nocturia subscales (IPSS Q7, $P<0.001)$; and IPSS-QOL score $(P<0.001)$ after treatment (Fig. 1b). There were no significant differences in voiding symptoms, including incomplete emptying, intermittency, weak stream, and straining before and after 12-week mirabegron add-on treatment.
In the entire patient, changes in the objective parameters of VV, Qmax, and PVR are shown in Fig. 2. VV on free uroflowmetry increased from $137.3 \pm$ $62.9 \mathrm{~mL}$ to $154.1 \pm 64.1 \mathrm{~mL}$ after treatment $(P=0.005)$. Similarly, Qmax improved from $9.1 \pm 3.7 \mathrm{~mL} / \mathrm{s}$ to $11.1 \pm$ $3.6 \mathrm{~mL} / \mathrm{s}(P=0.036)$. However, no significant change was detected in PVR (from $23.1 \pm 15.6 \mathrm{~mL}$ to $27.3 \pm 21.5 \mathrm{~mL}$, $P=0.349$ ).

Next, changes of these parameters on subjective symptoms and objective measurements depending on age (young-old and old-old group) were showed in Table 2. The total OABSS and nighttime frequency (OABSS Q2), and urgency (OABSS Q3) subscales were improved in both groups. However, urgency incontinence (OABSS Q4) was improved only in the young-old group $(P=0.021$; oldold group, $P=0.686$ ). Significant improvements were also observed in the total IPSS; IPSS-QOL; and frequency (IPSS Q2), urgency (IPSS Q4), and nocturia (IPSS Q7) subscales in both groups. No IPSS-related parameter significantly differed between the young-old group and the old-old group. However, although all IPSS parameters were unchanged or decreased in the young-old group after treatment, incomplete emptying (Q1), intermittency (Q3), weak stream (Q5), and straining (Q6) had a tendency to increase after treatment in the old-old group.

Among the objective symptoms, VV on free uroflowmetry increased after treatment in the young-old group $(P=0.012)$ but not in the old-old group $(P=0.113)$. There were no significant changes in the Qmax and PVR after treatment in either group.

A safety analysis was performed on all patients during the clinical trial. Two patients (4\%) complained of dry mouth. One patient (2\%) complained of constipation. However, since these adverse effects were very mild, the patients did not need to stop taking mirabegron. In addition, none of the patients with hypertension experienced worsening of their blood pressure levels. Hence, all patients completed this clinical study, including all scheduled examinations during the study period.

Table 1 Patients' characteristics

\begin{tabular}{|c|c|c|c|c|}
\hline & Overall & Young-old group & Old-old group & $P$ value $^{a}$ \\
\hline Number of patients (N/\%) & 50 & $22(44.0)$ & $28(56.0)$ & - \\
\hline Age (years) & $75.7 \pm 7.6$ & $68.7(2.7)$ & $81.1(5.3)$ & $<0.001$ \\
\hline Prostate volume (mL) & $33.7 \pm 8.6$ & $33.5(7.6)$ & $33.7(9.5)$ & 0.961 \\
\hline \multicolumn{5}{|c|}{ a1-adrenergic receptor blocker } \\
\hline Silodosin (N/\%) & $26(52.0)$ & $13(59.1)$ & $13(46.4)$ & \\
\hline Naftopidil & $15(30.0)$ & $5(22.7)$ & $10(35.7)$ & \\
\hline Tamsulosin & $8(16.0)$ & $3(13.6)$ & $5(17.9)$ & \\
\hline Urapidil & $1(2.0)$ & $1(4.5)$ & $0(0)$ & \\
\hline
\end{tabular}

Data are shown as mean \pm standard deviation

${ }^{a}$ Difference between the young-old group and old-old group 


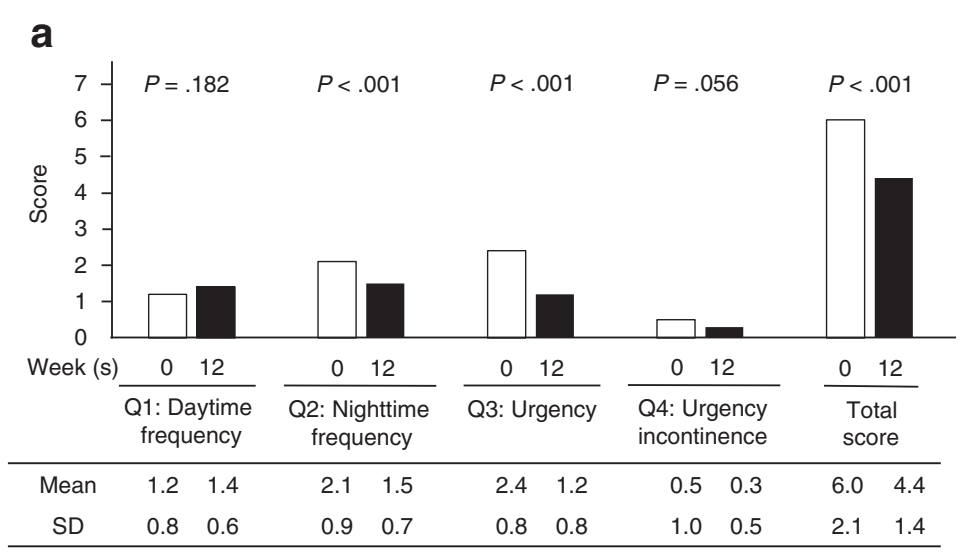

b
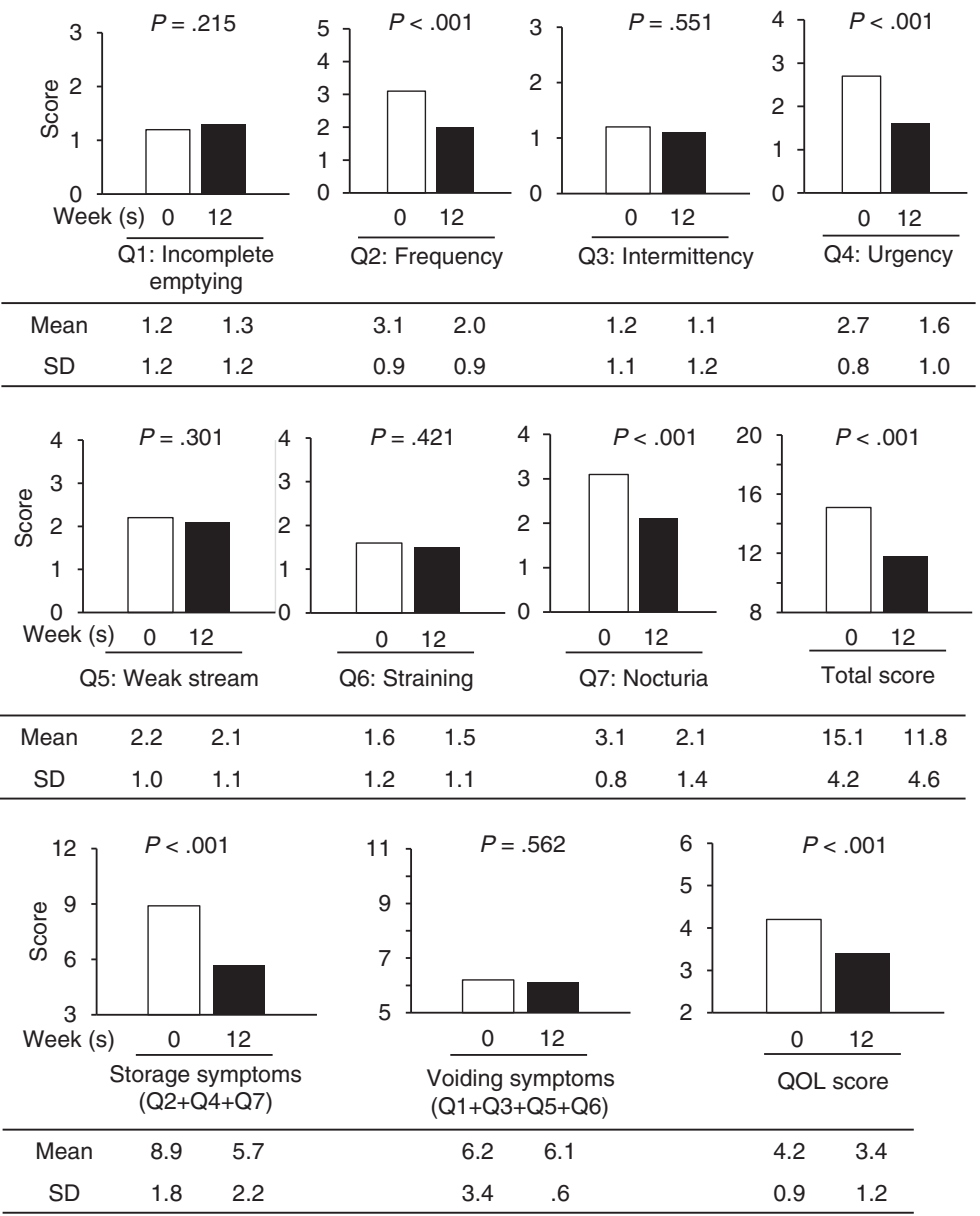

Fig. 1 Changes in subjective symptoms. a shows changes in the Overactive Bladder Symptom Score (OABSS). Combination therapy with a-1 adrenergic receptor blocker and mirabegron for 12 weeks significantly improved the total OABSS, nighttime frequency (Q2), and urgency (Q3). b shows the change in the International Prostate Symptom Score (IPSS). Combination therapy significantly improved the IPSS total score, IPSS-quality of life, and storage symptoms (frequency [Q2], urgency [Q4], nocturia [Q7], and IPSS-storage symptoms [Q2 + Q4 + Q7]). However, combination therapy did not affect voiding symptoms (incomplete emptying [Q1], intermittency [Q3], weak stream [Q5], straining [Q6], and IPSS-voiding symptoms [Q1 + Q3 + Q5 + Q6]). The white columns show the scores at 0 weeks, and the black columns show scores at 12 weeks. SD, standard deviation

\section{Discussion}

To the best of our knowledge, the present study is the first to focus on the efficacy of mirabegron additional therapy in elderly male patients with $\mathrm{OAB}$ after monotherapy with $\alpha 1$-adrenergic receptor blockers. Our findings indicated that mirabegron additional therapy was 


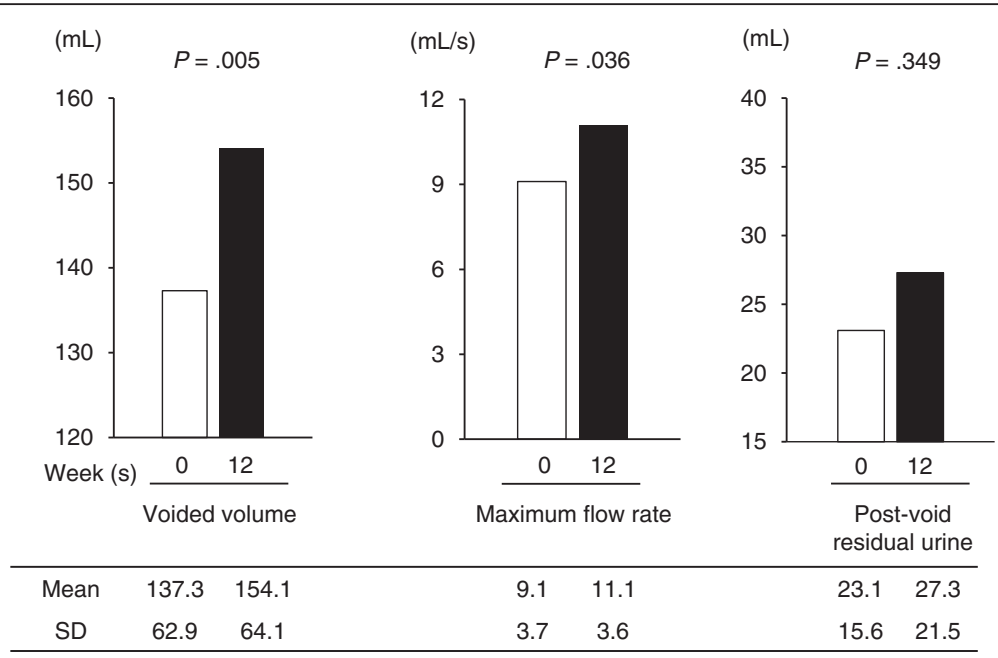

Fig. 2 Changes in the measurements of objective symptoms in patients overall. The white columns show the values at 0 weeks, and the black columns show those at 12 weeks. After 12 weeks of a1-adrenergic receptor blocker and mirabegron combination therapy, the voided volume and maximum flow rate improved significantly. Post-void residual urine increased at the end of the period; however, this change was not statistically significant. SD, standard deviation

Table 2 Changes in the values of the subjective and objective symptoms in each group of elderly male patients with overactive bladder

\begin{tabular}{|c|c|c|c|c|c|c|}
\hline & \multicolumn{3}{|c|}{ Young-old group $(N=22)$} & \multicolumn{3}{|c|}{ Old-old group $(N=28)$} \\
\hline & $0 \mathrm{~W}$ & $12 \mathrm{~W}$ & $P$ Value & $0 \mathrm{~W}$ & $12 \mathrm{~W}$ & $P$ Value \\
\hline \multicolumn{7}{|l|}{ OABSS } \\
\hline Q1 Daytime frequency & $1.1 \pm 0.7$ & $1.4 \pm 0.8$ & 0.307 & $1.1 \pm 0.8$ & $1.4 \pm 0.5$ & 0.148 \\
\hline Q2 Nighttime frequency & $2.1 \pm 1.0$ & $1.5 \pm 0.9$ & 0.034 & $2.0 \pm 0.8$ & $1.5 \pm 0.6$ & 0.005 \\
\hline Q3 Urgency & $2.7 \pm 1.1$ & $1.2 \pm 1.1$ & $<0.001$ & $2.2 \pm 0.4$ & $1.3 \pm 0.6$ & $<0.001$ \\
\hline Q4 Urgency incontinence & $0.9 \pm 1.3$ & $0.3 \pm 0.6$ & 0.021 & $0.2 \pm 0.4$ & $0.3 \pm 0.4$ & 0.686 \\
\hline Total score & $6.5 \pm 2.7$ & $4.4 \pm 1.6$ & 0.004 & $5.6 \pm 1.3$ & $4.2 \pm 1.2$ & $<0.001$ \\
\hline \multicolumn{7}{|l|}{ IPSS } \\
\hline Q1 Incomplete emptying & $1.2 \pm 1.4$ & $1.2 \pm 1.3$ & 1.000 & $1.2 \pm 1.0$ & $1.4 \pm 1.2$ & 0.093 \\
\hline Q2 Frequency & $3.0 \pm 1.1$ & $2.0 \pm 1.0$ & 0.001 & $3.1 \pm 0.7$ & $2.1 \pm 0.9$ & $<0.001$ \\
\hline Q3 Intermittency & $1.4 \pm 1.3$ & $1.2 \pm 1.3$ & 0.205 & $1.0 \pm 1.0$ & $1.1 \pm 1.2$ & 0.529 \\
\hline Q4 Urgency & $2.8 \pm 0.8$ & $1.7 \pm 0.9$ & $<0.001$ & $2.6 \pm 0.8$ & $1.5 \pm 1.0$ & $<0.001$ \\
\hline Q5 Weak stream & $2.2 \pm 1.1$ & $2.0 \pm 1.2$ & 0.142 & $2.2 \pm 1.0$ & $2.3 \pm 1.0$ & 0.689 \\
\hline Q6 Straining & $2.0 \pm 1.5$ & $1.7 \pm 1.4$ & 0.110 & $1.3 \pm 0.8$ & $1.4 \pm 0.9$ & 0.529 \\
\hline Q7 Nocturia & $3.3 \pm 0.8$ & $2.3 \pm 1.4$ & 0.001 & $2.9 \pm 0.8$ & $1.9 \pm 0.9$ & $<0.001$ \\
\hline Total score & $16.0 \pm 5.1$ & $12.0 \pm 5.3$ & $<0.001$ & $14.5 \pm 3.3$ & $11.7 \pm 4.1$ & $<0.001$ \\
\hline Storage symptoms (Q2 + Q4 + Q7) & $9.1 \pm 1.9$ & $6.0 \pm 2.5$ & $<0.001$ & $8.7 \pm 5.6$ & $5.6 \pm 2.0$ & $<0.001$ \\
\hline Voiding symptoms (Q1 + Q3 + Q5 + Q6) & $6.8 \pm 4.4$ & $6.0 \pm 4.4$ & 0.029 & $5.8 \pm 2.5$ & $6.1 \pm 3.0$ & 0.102 \\
\hline QOL score & $4.3 \pm 1.0$ & $3.5 \pm 1.4$ & 0.006 & $4.1 \pm 0.8$ & $3.2 \pm 1.0$ & $<0.001$ \\
\hline \multicolumn{7}{|l|}{ Urodynamic study } \\
\hline$W(m L)$ & $141.0 \pm 78.1$ & $169.5 \pm 74.0$ & 0.012 & $134.4 \pm 49.2$ & $142.0 \pm 53.4$ & 0.133 \\
\hline Qmax (mL/s) & $9.1 \pm 3.0$ & $9.9 \pm 2.7$ & 0.159 & $9.1 \pm 2.2$ & $12.0 \pm 12.4$ & 0.116 \\
\hline PVR (mL) & $27.4 \pm 41.8$ & $22.1 \pm 22.7$ & 0.879 & $26.5 \pm 17.3$ & $30.4 \pm 25.9$ & 0.190 \\
\hline
\end{tabular}


effective for those whose $\mathrm{OAB}$ was not controlled with $\alpha 1$-adrenergic receptor blockers, according to the OABSS and IPSS. Our results also demonstrated that mirabegron had no suppressive effects on voiding function on uroflowmetry and PVR. In addition, regardless of the patient's age, mirabegron add-on therapy was considered effective and safe to take orally.

In elderly patients with benign prostatic hyperplasia, an $\alpha 1$-adrenergic receptor blocker significantly improved LUTS, especially voiding dysfunction. However, some patients may continue to suffer from storage symptoms such as urgency and frequency. For these patients, some studies have suggested that combination therapy with an $\alpha 1$-adrenergic receptor blocker and anti-muscarinic drug is effective $[18,19]$. However, because of the impaired physiological function of elderly people, anti-muscarinic drugs carry the risk for adverse events. In fact, there is a significant incidence of peripheral anti-muscarinic adverse events such as dry mouth, constipation, tachycardia, cognitive dysfunction, and voiding dysfunction in elderly patients [20, 21]. Voiding dysfunction, in particular, due to male LUTS, might lead to excessive residual urine, urinary tract infection, and post-renal renal failure.

Mirabegron, a $\beta 3$-adrenergic receptor agonist, is a new type of agent for $\mathrm{OAB}$, with a reported adverse effect rate almost as low as that of a placebo $[15,22]$. However, recently, concerns have been raised regarding the use of mirabegron to treat $\mathrm{OAB}$ patients with severe hypertension (systolic blood pressure $\geq 180 \mathrm{mmHg}$ and/or diastolic blood pressure $\geq 110 \mathrm{mmHg}$ ) [23]. In addition, no studies have targeted elderly male patients 65 years old and over, who are more prone to experiencing complications than younger patients.

According to the present study, mirabegron additional therapy improved storage symptoms on the OABSS and IPSS regardless of age. In addition, mirabegron additional therapy improved storage symptoms and voiding symptoms on the IPSS in the young-old patient group. Previous studies have reported that mirabegron improved the OABSS and the total and storage symptoms on the IPSS in male patients with $\mathrm{OAB}[15,16,24]$. Moreover, Wada et al. suggested that mirabegron addon treatment with tamsulosin improved storage symptoms and voiding symptoms [16]. However, these previous studies were complex, as they included patients of various ages and they had small sample sizes; no study has focused only on older male patients. Ichihara et al. reported that combination therapy with tamsulosin and mirabegron was effective for persistent OAB symptoms with benign prostatic obstruction after tamsulosin monotherapy [15]. They divided the patients into two groups, tamsulosin monotherapy $(N=38)$ and combination therapy with tamsulosin and mirabegron $(N=38)$.
Although average age of their study cohort was very similar to that of the present study $(74.5 \pm 8.2 \mathrm{vs} .75 .7 \pm$ 7.6 years), they included male patients aged 50 years or older. Hence they did not target only elderly male LUTS patients. In addition, the number of patients receiving combination therapy with tamsulosin and mirabegron was lower in the previous study compared to ours.

Upon further stratifying our study subjects according to age, our results suggested that voiding symptoms worsened slightly after treatment in the old-old patient group, but this difference was not statistically significant. These findings indicate that the use of mirabegron in elderly patients should be carefully monitored, especially in older patients .

The objective symptoms VV and Qmax on uroflowmetry were improved after treatment in patients overall. $\mathrm{VV}$ was particularly improved after treatment in youngold patients. However, objective symptoms did not change significantly in the old-old patient group. A previous pressure-flow study reported that mirabegron did not affect urinary bladder contraction even if older male patients were included in the analysis $[16,25]$. However, these studies indicated that mirabegron therapy possibility increased PVR, although the change was not statistically significant. In our study, we obtained similar results for PVR. The older patients' voiding functions declined physiologically, and their initial PVR volume was higher than that of the younger patients [26]. Although many clinicians think that mirabegron is associated with fewer problems in terms of voiding function than anticholinergic agents, it is necessary to consider changes in both the subjective and objective symptoms after treatment with mirabegron, especially in old-old patients.

In the present study, only three patients $(6 \%)$ had mild adverse effects ( 2 patients, thirst; 1 patient, constipation), and all patients continued to take mirabegron during the study period. None of the patients with hypertension experienced worsening of their blood pressure level, although hypertension was well-controlled by medication or not severe in all cases in the present study. Hence, it appears that mirabegron can be used safely, and it has good tolerability. Previous studies have reported that typical adverse events such as dry mouth and constipation occurred at a similar incidence between mirabegron and placebo treatment $[10,12,27]$. The incidence of dry mouth with mirabegron, in particular, is three- to four-fold lower than that with tolterodine. As noted in a meta-analysis, anti-muscarinic drugs are associated with a $29.6 \%$ incidence of dry mouth [27]. As dry mouth is reported to be an important factor determining persistence, the favorable tolerability profile of mirabegron may result in improved treatment adherence compared with anti-muscarinic drugs, which has important implications for patient outcome [10]. Many elderly 
people suffer from constipation and dry mouth; thus mirabegron may be convenient to administer in the elderly with $\mathrm{OAB}[28,29]$.

The present study has several limitations, the major one being that the number of patients included was very small. The observation period was also limited to only 12 weeks. In addition, this study was open label, not placebo controlled. Moreover, patients with relatively mild voiding symptoms prior to mirabegron treatment (with IPSS subscale scores for voiding symptoms of $6.8 \pm 1.4$, and PVR of $27.4 \pm 41.8 \mathrm{~mL}$ ) and with low prostate volume $(33.7 \pm 8.6 \mathrm{~mL})$ unlikely to conducting the urinary dysfunction were mainly included in this study. These factors may have contributed to the low complication rate observed in this study. However, despite these limitations, this is the first prospective study that specifically evaluated elderly male patients with $O A B$ who were administered mirabegron additional therapy after treatment with $\alpha 1$-adrenergic receptor blockers. In recent years, there has been growing interest in the efficacy and safety of mirabegron for elderly patients [30]. We believe that in spite of its small sample size, this investigation contributes important information to the selection of treatment strategies in elderly patients with lower urinary tract symptoms.

\section{Conclusions}

Our results indicate that mirabegron additional treatment is effective, safe, and tolerable therapy for persistent $\mathrm{OAB}$ in elderly male patients after monotherapy with $\alpha 1$-adrenergic receptor blockers. In addition, mirabegron additional therapy was considered effective regardless of the patient's age.

\section{Abbreviations \\ IPSS, international prostate symptom score; LUTS, lower urinary tract symptoms; $\mathrm{OAB}$, overactive bladder; OABSS, overactive bladder symptom; PVR, post-void residual urine volume; Qmax, maximum flow rate; QOL, quality of life; $\mathrm{W}$, voided volume}

\section{Acknowledgements}

The authors are grateful to Mr. Takumi Shimogama for their outstanding support.

\section{Funding}

The work was not supported by any grants.

\section{Availability of data and materials}

Raw dataset from patients cannot be shared since the informed consent from the participants at the time of the study recruitment only included the publication of the study results but not sharing them in public.

\section{Authors' contributions}

TM and YM performed the design of the study and drafted the manuscript. $\mathrm{KK}$ and MY contributed experiments and data analysis, KO and AA helped the experiments and data analysis. HS conceived of and supervised the work. All authors read and approved the final manuscript.

\section{Competing interests}

The authors declare that they have no competing interests.
Consent for publication

Not applicable.

Ethics approval and consent to participate

This study was approved by the Nagasaki University Hospital Ethical Committee, and it was performed in accordance with the principles of the Declaration of Helsinki. All patients provided written informed consent.

Received: 6 March 2016 Accepted: 22 July 2016

Published online: 29 July 2016

\section{References}

1. Abrams P, Cardozo L, Fall M, Griffiths D, Rosier P, Ulmsten U, et al. The standardisation of terminology of lower urinary tract function: report from the Standardisation Sub-committee of the International Continence Society. Neurourol Urodyn. 2002;21(2):167-78

2. Wagg A, Cardozo L, Nitti WW, Castro-Diaz D, Auerbach S, Blauwet MB, et al. The efficacy and tolerability of the $\beta 3$-adrenoceptor agonist mirabegron for the treatment of symptoms of overactive bladder in older patients. Age Ageing. 2014;43(5):666-75.

3. Stewart WF, Van Rooyen JB, Cundiff GW, Abrams P, Herzog AR, Corey R, et al. Prevalence and burden of overactive bladder in the United States. World J Urol. 2003;20(6):327-36.

4. Brown JS, McGhan WF, Chokroverty S. Comorbidities associated with overactive bladder. Am J Manag Care. 2000;6(11 Suppl):S574-9.

5. McGhan WF. Cost effectiveness and quality of life considerations in the treatment of patients with overactive bladder. Am J Manag Care. 2001;7(2 Suppl):S62-75.

6. D'Souza AO, Smith MJ, Miller LA, Doyle J, Ariely R. Persistence, adherence, and switch rates among extended-release and immediate-release overactive bladder medications in a regional managed care plan. J Manag Care Pharm. 2008;14(3):291-301.

7. Benner JS, Nichol MB, Rovner ES, Jumadilova Z, Alvir J, Hussein M, et al. Patient-reported reasons for discontinuing overactive bladder medication. BJU Int. 2010;105(9):1276-82.

8. Homma Y, Araki I, Igawa Y, Ozono S, Gotoh M, Yamanishi T, Yokoyama O, Yoshida M. Japanese Society of Neurogenic Bladder. Clinical guideline for male lower urinary tract symptoms. Int J Urol. 2009;16(10):775-90.

9. Homma Y, Gotoh M, Yokoyama O, Masumori N, Kawauchi A, Yamanishi T, Ishizuka O, Seki N, Kamoto T, Nagai A, Ozono S. Japanese Urological Association. Outline of JUA clinical guidelines for benign prostatic hyperplasia. Int J Urol. 2011;18(11):741-56.

10. Chapple CR, Kaplan SA, Mitcheson D, Blauwet MB, Huang M, Siddiqui E, et al. Mirabegron $50 \mathrm{mg}$ once-daily for the treatment of symptoms of overactive bladder: an overview of efficacy and tolerability over 12 weeks and 1 year. Int J Urol. 2014:21(10):960-7.

11. Imran M, Najmi AK, Tabrez S. Mirabegron for overactive bladder: a novel, first-in-class ß3-agonist therapy. Urol J. 2013;10(3):935-40.

12. Khullar V, Amarenco G, Angulo JC, Cambronero J, Høye K, Milsom I, et al. Efficacy and tolerability of mirabegron, a $\beta(3)$-adrenoceptor agonist, in patients with overactive bladder: results from a randomised EuropeanAustralian phase 3 trial. Eur Urol. 2013;63(2):283-95.

13. Chapple CR, Kaplan SA, Mitcheson D, Klecka J, Cummings J, Drogendijk T, et al. Randomized double-blind, active-controlled phase 3 study to assess 12 month safety and efficacy of mirabegron, a $\beta(3)$-adrenoceptor agonist, in overactive bladder. Eur Urol. 2013;63(2):296-305.

14. Otsuki H, Kosaka T, Nakamura K, Mishima J, Kuwahara Y, Tsukamoto T. $\beta 3$-Adrenoceptor agonist mirabegron is effective for overactive bladder that is unresponsive to antimuscarinic treatment or is related to benign prostatic hyperplasia in men. Int Urol Nephrol. 2013;45(1):53-60.

15. Ichihara K, Masumori N, Fukuta F, Tsukamoto T, Iwasawa A, Tanaka Y. A randomized controlled study of the efficacy of tamsulosin monotherapy and its combination with mirabegron for overactive bladder induced by benign prostatic obstruction. J Urol. 2015;193(3):921-6.

16. Wada N, luchi H, Kita M, Hashizume K, Matsumoto S, Kakizaki H. Urodynamic Efficacy and safety of mirabegron add-on treatment with tamsulosin for Japanese male patients with overactive bladder. LUTS Low Urin Tract Symptoms. 2015:n/a-n/a. doi:10.1111/luts.12091.

17. Homma Y, Yoshida M, Seki N, Yokoyama O, Kakizaki H, Gotoh M, et al. Symptom assessment tool for overactive bladder syndrome-overactive bladder symptom score. Urology. 2006;68(2):318-23. 
18. Takeda M, Nishizawa O, Gotoh M, Yoshida M, Takahashi S, Masumori N. Clinical efficacy and safety of imidafenacin as add-on treatment for persistent overactive bladder symptoms despite a-blocker treatment in patients with BPH: the ADDITION study. Urology. 2013;82(4):887-93.

19. Chapple C, Herschorn S, Abrams P, Sun F, Brodsky M, Guan Z. Tolterodine treatment improves storage symptoms suggestive of overactive bladder in men treated with alpha-blockers. Eur Urol. 2009;56(3):534-41.

20. Buser N, Ivic S, Kessler TM, Kessels AGH, Bachmann LM. Efficacy and adverse events of antimuscarinics for treating overactive bladder: network meta-analyses. Eur Urol. 2012;62(6):1040-60.

21. Gacci M, Novara G, De Nunzio C, Tubaro A, Schiavina R, Brunocilla E, et al. Tolterodine extended release in the treatment of male OAB/storage LUTS: a systematic review. BMC Urol. 2014;14:84. doi:10.1186/1471-2490-14-84.

22. Yamaguchi $O$, Marui $E$, Kakizaki $H$, Homma $Y$, Igawa $Y$, Takeda $M$, et al. Phase III, randomised, double-blind, placebo-controlled study of the $\beta 3$ adrenoceptor agonist mirabegron, 50 mg once daily, in Japanese patients with overactive bladder. BJU Int. 2014;113(6):951-60.

23. Drug Safety Update Mirabegron (Betmiga ${ }^{\circledR}$ ): risk of severe hypertension and associated cerebrovascular and cardiac events. Medicines and Healthcare Products Regulatory Agency. https://www.gov.uk/drug-safety-update/. Accessed 27 July 2016.

24. Maeda T, Kikuchi E, Hasegawa M, Ishioka K, Hagiwara M, Miyazaki Y, et al. Solifenacin or mirabegron could improve persistent overactive bladder symptoms after dutasteride treatment in patients with benign prostatic hyperplasia. Urology. 2015;85(5):1151-5.

25. Nitti WW, Rosenberg S, Mitcheson DH, He W, Fakhoury A, Martin NE. Urodynamics and safety of the $\beta 3$-adrenoceptor agonist mirabegron in males with lower urinary tract symptoms and bladder outlet obstruction. J Urol. 2013;190(4):1320-7.

26. Matsuo T, Oba K, Miyata Y, Igawa T, Sakai H. Four cases of urinary dysfunction associated with sacral herpes zoster. Hinyokika Kiyo. 2014;60(2):87-90.

27. Chapple CR, Khullar V, Gabriel Z, Muston D, Bitoun CE, Weinstein D. The effects of antimuscarinic treatments in overactive bladder: an update of a systematic review and meta-analysis. Eur Urol. 2008:54(3):543-62.

28. Bouras EP, Tangalos EG. Chronic constipation in the elderly. Gastroenterol Clin North Am. 2009;38(3):463-80

29. Tanida T, Ueta E, Tobiume A, Hamada T, Rao F, Osaki T. Influence of aging on candidal growth and adhesion regulatory agents in saliva. J Oral Pathol Med. 2001;30(6):328-35.

30. Wagg A, Nitti W, Kelleher C, Castro-Diaz D, Siddiqui E, Berner T. Oral pharmacotherapy for overactive bladder in older patients: mirabegron as a potential alternative to antimuscarinics. Curr Med Res Opin. 2016:32(4):621-38

\section{Submit your next manuscript to BioMed Central and we will help you at every step:}

- We accept pre-submission inquiries

- Our selector tool helps you to find the most relevant journal

- We provide round the clock customer support

- Convenient online submission

- Thorough peer review

- Inclusion in PubMed and all major indexing services

- Maximum visibility for your research

Submit your manuscript at www.biomedcentral.com/submit 